Calculation of Radiation Damage in SLAC Targets

B. D. Wirth, P. Monasterio, W. Stein

April 3, 2008 
This document was prepared as an account of work sponsored by an agency of the United States government. Neither the United States government nor Lawrence Livermore National Security, LLC, nor any of their employees makes any warranty, expressed or implied, or assumes any legal liability or responsibility for the accuracy, completeness, or usefulness of any information, apparatus, product, or process disclosed, or represents that its use would not infringe privately owned rights. Reference herein to any specific commercial product, process, or service by trade name, trademark, manufacturer, or otherwise does not necessarily constitute or imply its endorsement, recommendation, or favoring by the United States government or Lawrence Livermore National Security, LLC. The views and opinions of authors expressed herein do not necessarily state or reflect those of the United States government or Lawrence Livermore National Security, LLC, and shall not be used for advertising or product endorsement purposes.

This work performed under the auspices of the U.S. Department of Energy by Lawrence Livermore National Laboratory under Contract DE-AC52-07NA27344. 
UCB-NE-5015

Page 1 of 13

\title{
Calculation of radiation damage in SLAC targets
}

\author{
B.D. Wirth, P. Monasterio and W. Stein
}

UC Berkeley Nuclear Engineering Department Technical Report, UCB-NE-5015

November 2005

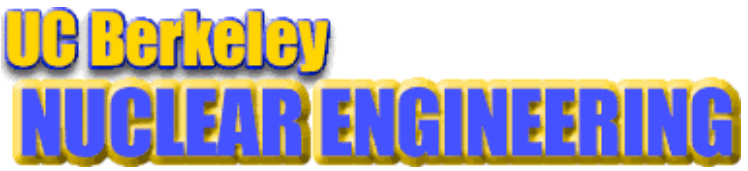


UCB-NE-5015

Page 2 of 13

Calculation of radiation damage in SLAC targets

B. D. Wirth, P. Monasterio and W. Stein

\begin{abstract}
Ti-6Al-4V alloys are being considered as a positron producing target in the Next Linear Collider, with an incident photon beam and operating temperatures between room temperature and $300^{\circ} \mathrm{C}$. Calculations of displacement damage in Ti-6Al-4V alloys have been performed by combining high-energy particle FLUKA simulations with SPECTER calculations of the displacement cross section from the resulting energy-dependent neutron flux plus the displacements calculated from the Lindhard model from the resulting energy-dependent ion flux. The radiation damage calculations have investigated two cases, namely the damage produced in a Ti-6Al-4V SLAC positron target where the irradiation source is a photon beam with energies between 5 and $11 \mathrm{MeV}$. As well, the radiation damage dose in displacements per atom, dpa, has been calculated for a mono-energetic $196 \mathrm{MeV}$ proton irradiation experiment performed at Brookhaven National Laboratory (BLIP experiment). The calculated damage rate is 0.8 dpa/year for the Ti-6Al-4V SLAC photon irradiation target, and a total damage exposure of 0.06 dpa in the BLIP irradiation experiment. In both cases, the displacements are predominately ( $80 \%$ ) produced by recoiling ions (atomic nuclei) from photo-nuclear collisions or protonnuclear collisions, respectively. Approximately 25\% of the displacement damage results from the neutrons in both cases.

Irradiation effects studies in titanium alloys have shown substantial increases in the yield and ultimate strength of up to $500 \mathrm{MPa}$ and a corresponding decrease in uniform ductility for neutron and high energy proton irradiation at temperatures between 40 and $300^{\circ} \mathrm{C}$. Although the data is limited, there is an indication that the strength increases will saturate by doses on the order of a few dpa. Microstructural investigations indicate that the dominant features responsible for the strength increases were dense precipitation of a $\beta$ (body-centered cubic) phase precipitate along with a high number density of dislocation loops.
\end{abstract}


UCB-NE-5015

Page 3 of 13

\section{Introduction}

Radiation damage within the positron-producing targets of high-energy linear accelerators is anticipated to be lifetime limiting within the next generation of facilities, such as the Next Linear Collider, NLC [1]. In the NLC, radiation doses are expected to be significantly larger than in current and previous generations of linear accelerators. Targets used in the Stanford Linear Collider [2] (SLC) provide a source of evidence for the damage accumulated in Tungsten-Rhenium (W-Re) targets. A number of alternate target materials and primary beams have been evaluated as NLC target candidates in recent years [3-4]. This report describes the results of radiation damage calculations of Ti-6Al-4V positron targets with a 5-11 MeV photon beam, and summarizes the available literature database of irradiation effects in Ti-6Al-4V alloys. The report is organized as follows, Section 2 describes the approach used to calculate the radiation damage levels in displacements per atom (dpa) in Ti-6Al-4V as irradiated by a photon or high energy proton beam. Section 3 presents the results of the calculation, while Section 4 summarizes the literature database and Section 5 summarizes the report.

\section{Modeling approach}

The dpa calculations combined multiple theoretical methods and computer codes to calculate the displacement, as indicated in the flowsheet presented in Figure 1. The incident beam, either the photon energy spectrum for the positron targets or the proton beam for the BLIP irradiation experiments, was statistically sampled by Heinz Vincke at SLAC as input to the FLUKA code $[5,6]$. FLUKA calculated the nuclear interactions of the incident beam with the target and tracked the resulting nuclear reaction products. The resulting output was provided for the radiation damage calculations and consisted of secondary photons, neutrons, protons, deuterons, tritons, ${ }^{3} \mathrm{He}$, and alpha particles along with the recoiling nuclei from the nuclear reaction. The FLUKA output includes both the position and momentum of the energetic particles. Five separate FLUKA runs were performed for the photon target, with 20 million primary photons statistically sampled from the incident photon energy spectrum, with the sampling weighted toward the higher energy photons above the threshold energy to induce photo-nuclear reactions. Ten separate FLUKA runs were performed for the BLIP proton irradiations, with 1 million primary protons sampled in each run. The separate FLUKA runs 
UCB-NE-5015

Page 4 of 13

provide an assessment of the error in dpa cross-sections, with the standard error on the order of $1 \%$ or less.

The neutron and ion populations (position, kinetic energy and momentum vector) output from the FLUKA simulations were then treated separately in the damage calculation. The calculation of the displacements induced by the neutrons involved collecting all of the neutrons into an energy dependent neutron flux for input into the SPECTER code [7] to calculate the displacement (dpa) cross-section. The calculation of the displacements induced by the ions was performed analytically by considering the partitioning of ion energy into electronic excitation without damage creation and nuclear collisions that produce defects. The displacement calculations are described in more detail below.

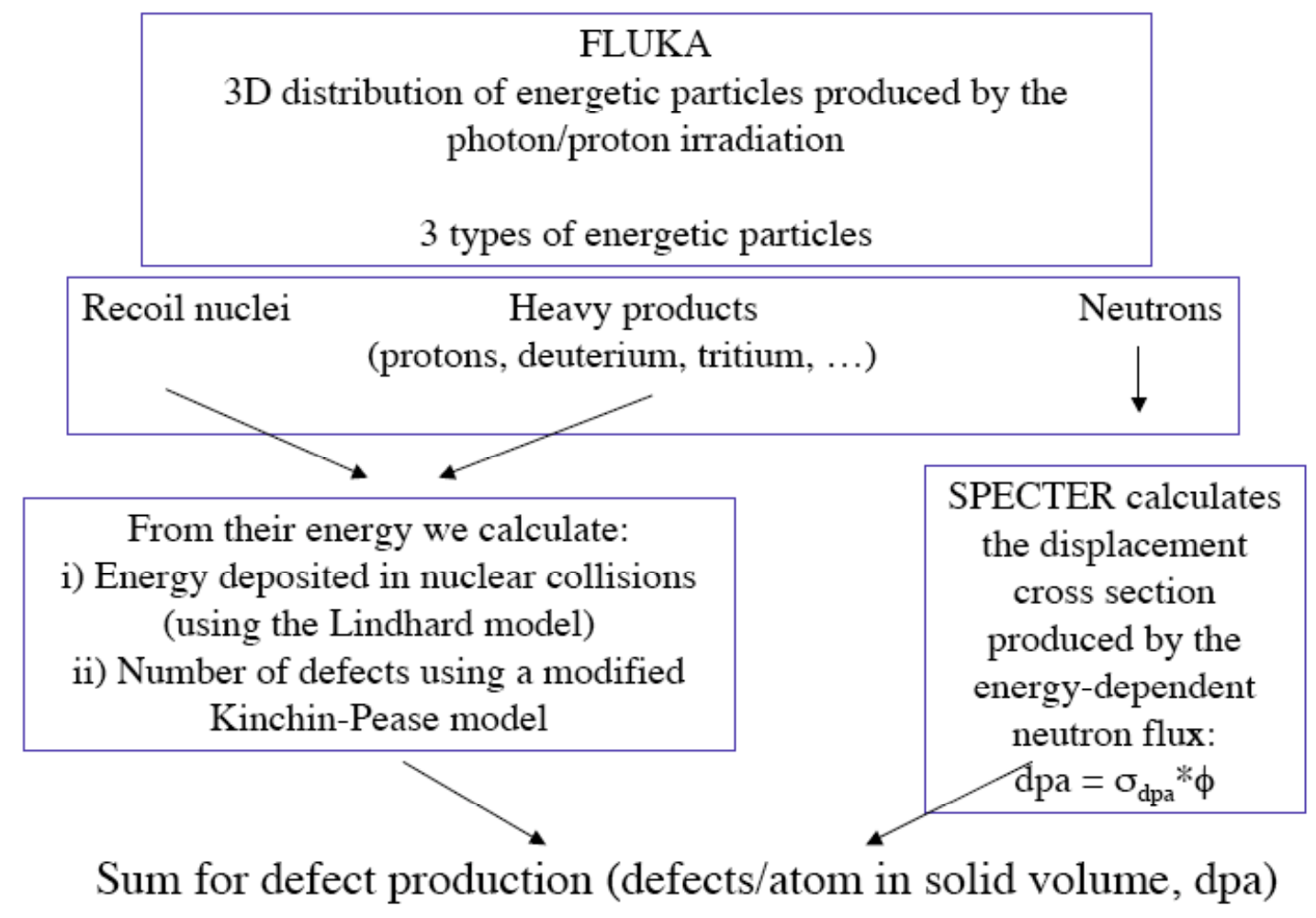

Figure 1. Approach to calculating the displacement damage in dpa for Ti-6Al-4V alloys irradiated with a 5-11 MeV photon beam or an $\sim 190 \mathrm{MeV}$ proton beam.

\subsection{SPECTER calculations}

The SPECTER code calculates the number of displacements, in addition to hydrogen and helium gas generation, for an input neutron energy flux spectra based on a differential cross section library [7]. Thus, the calculation of the displacements induced by neutrons involves first 
UCB-NE-5015

Page 5 of 13

incorporating all neutrons generated by photon or proton induced nuclear reactions from the FLUKA output files into a energy-dependent flux for input into SPECTER. Based on the total flux (fluence) associated with this energy-dependent neutron flux spectrum, the SPECTER calculated dpa values are then converted back to a dpa cross-section, $\sigma_{\mathrm{dpa}}$, for calculation of the total neutron-induced dpa based on the photon (proton) produced neutron flux, $\phi$, as

$$
\mathrm{dpa}_{\mathrm{n}}=\sigma_{\mathrm{dpa}} \phi \mathrm{t}
$$

Figure 2 shows the energy dependent neutron energy spectrum obtained from the FLUKA simulations of an incident 5 to $11 \mathrm{MeV}$ photon beam on the Ti-6Al-4V target. As can be seen, vast majority of the neutrons have energies below $1 \mathrm{MeV}$, although the tail of the distribution extends beyond $40 \mathrm{MeV}$. Care must be taken when calculating the appropriate neutron flux, $\phi$, to properly account for the sampling weight of the incident photons in the FLUKA calculation. The flux has been calculated by multiplying the total number of neutrons produced in a FLUKA calculation by the weight of the primary photon creating the neutron divided by the total weight of all photons simulated by FLUKA, and then multiplying this product by the anticipated photon flux. Thus,

$$
\phi=\frac{\sum_{\mathrm{i}=1}^{\# \text { primary particle (neutron) weight }}}{\text { total weight of primary particles }} * \mathrm{I}_{\text {photon }}
$$

where $\mathrm{I}_{\text {photon }}$ is the incident photon flux anticipated on the Ti-6Al-4V target. This incident photon flux was based on $6.6 \times 10^{21}$ photons per year striking the target with a spot size radius of 0.075 $\mathrm{cm}\left(\right.$ e.g., $3.7 \times 10^{23}$ photons/[ $\mathrm{cm}^{2}$-year $\left.]\right)$. 
UCB-NE-5015

Page 6 of 13

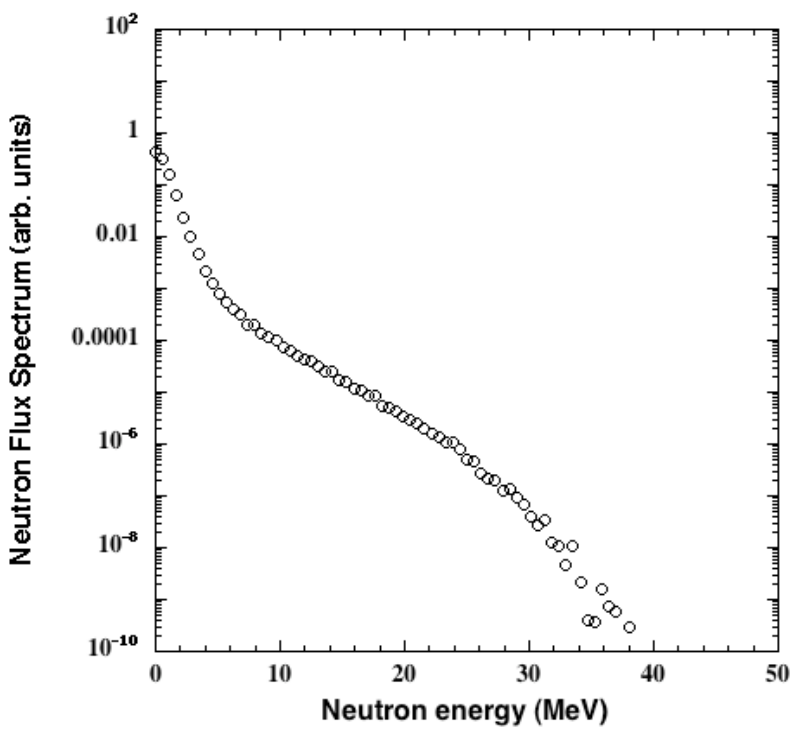

Figure 2. Energy-dependent neutron flux spectra produced by a 5-11 MeV photon beam incident on a Ti$6 \mathrm{Al}-4 \mathrm{~V}$ target.

\subsection{Calculation of ion damage}

The ion damage from energetic protons, deuterons, tritons, ${ }^{3} \mathrm{He}$, alpha particles, etc. plus the resulting recoiling nuclei from a photon (proton) - nuclear interaction was calculated from the Lindhard model $[8,9]$, which partitions the ions kinetic energy into electronic excitations and nuclear excitations. The Lindhard damage model assumes that displacement damage is produced only by the nuclear collisions. The number of displacements, $v$, produced in a solid of mass $\left(\mathrm{m}_{\mathrm{s}}\right.$ and charge $Z_{s}$ ) by an ion (mass $m_{i}$ and charge $Z_{i}$ ) with kinetic energy $T$ is:

$$
\begin{aligned}
& v=\xi\left(\mathrm{T}, \mathrm{Z}_{\mathrm{i}}, \mathrm{Z}_{\mathrm{s}}\right) \frac{\mathrm{T}}{2 \mathrm{E}_{\mathrm{d}}} \\
& \xi(\varepsilon)=\frac{1}{1+0.13\left(3.4 \varepsilon^{1 / 6}+0.4 \varepsilon^{3 / 4}+\varepsilon\right)} \\
& \varepsilon=\frac{\mathrm{T}}{\left(2 \mathrm{Z}_{\mathrm{i}} \mathrm{Z}_{\mathrm{s}} \mathrm{e}^{2} / \mathrm{a}\right)} \\
& \mathrm{a}=\frac{0.88 \mathrm{a}_{\text {Bohr }}}{\left(\mathrm{Z}_{\mathrm{i}}^{2 / 3}+\mathrm{Z}_{\mathrm{s}}^{2 / 3}\right)^{1 / 2}}
\end{aligned}
$$


UCB-NE-5015

Page 7 of 13

where $\mathrm{e}^{2}$ is $14.4 \mathrm{eV} / \AA$, $\mathrm{a}_{\mathrm{Bohr}}$ is $0.529 \AA$ and $\mathrm{E}_{\mathrm{d}}$ is the effective displacement energy for the Ti6Al-4V alloy. The recommended displacement energies are $40 \mathrm{eV}$ for $\mathrm{Ti}$ and $\mathrm{V}$, and $27 \mathrm{eV}$ for $\mathrm{Al}[7]$, resulting in a mass fraction averaged value of $39 \mathrm{eV}$.

The number of displacements, induced by each ion type (on a per incident photon basis) were converted to dpa and then summed. The conversion to dpa was performed by dividing the displacements, $v$, by the cylindrical target volume containing the recoils $(\mathrm{r} \sim 0.25 \mathrm{~cm}$ and $\mathrm{L}=1.5$ $\mathrm{cm}$ for the NLC photon target), multiplying by a weighting factor consisting of the appropriate ion weight divided by the total weight of the primary particles in the FLUKA simulation and multiplied by the atomic volume of Ti-6Al-4V $\left(\Omega=1.75 \times 10^{-23} \mathrm{~cm}^{3} /\right.$ atom $)$. Thus,

$$
\begin{aligned}
& \left.\mathrm{dpa}_{\text {ions }}=v^{\prime} \text { (dpa per incident photon }\right) *(\# \text { incident photons }) \\
& v^{\prime}=\sum_{\mathrm{j}=1}^{\text {all energetic ions }} v\left(\mathrm{~T}, \mathrm{Z}_{\mathrm{i}}, \mathrm{Z}_{\mathrm{s}}\right) * \frac{\text { weight,ion } \mathrm{j}}{\text { total weight }} * \Omega
\end{aligned}
$$

where the number of incident photons is $6.6 \times 10^{21}$ photons/year. It should be noted that the displacements produced by energetic ions is known to be much more spatially heterogeneous than that created by neutrons, and thus the ion dpa damage calculated using Equations 3 and 4 do not account for the possibility of somewhat higher peak damage values at the positions of the highest photon (proton) - nuclear reaction density.

\section{Radiation damage calculations}

\subsection{SLAC target}

Table 1 presents the calculated displacement damage resulting from energetic ions for the Ti-6Al-4V positron target, irradiated by a 5 to $11 \mathrm{MeV}$ photon beam. The majority of the displacement damage is produced by the energetic alpha particles $\left({ }^{4} \mathrm{He}\right)$, the recoiling nuclei following a photo-nuclear reaction, and energetic protons. For $6.6 \times 10^{21}$ photons/year incident in each sample spot of the target, the displacement damage due to the energetic ions is 0.606 dpa/year.

A spectral averaged dpa cross section, $\sigma_{\mathrm{dpa}}$, of 532 barns was obtained from the SPECTER calculation for an incident neutron energy flux spectrum as shown in Figure 2. This 
UCB-NE-5015

Page 8 of 13

value equates to $2.67 \times 10^{-23} \mathrm{dpa} /$ incident photon - or a displacement damage rate due to photonnuclear produced neutrons of $0.176 \mathrm{dpa} /$ year.

Thus the total displacement damage in the Ti-6Al-4V positron target induced by a 5 to 11 $\mathrm{MeV}$ incident photon beam is approximately $0.8 \mathrm{dpa} /$ year $(0.782 \mathrm{dpa} /$ year $)$. Notably, the fraction of the displacements produced by neutrons is about one quarter $(22.5 \%)$ that produced by energetic ions. The fraction of damage produced by neutrons versus energetic ions is the opposite of previous calculations performed by Maria Jose Caturla [3,4], where the majority ( $\sim 80 \%)$ of the damage was calculated to be caused by neutrons. Further comparisons, including a re-analysis of previous calculations, should be performed to clarify this discrepancy. Although it is tempting to conclude that the differences relate to the different treatment of neutron damage production. It is also important to note that the current dpa calculations have not included the effect of in-cascade recombination of point defects as did the previous calculations by Caturla $[3,4]$.

Table 1. Calculated radiation damage for energetic ions as the number of displacements and dpa/incident photon.

\begin{tabular}{|c|c|c|}
\hline Ion & Weighted \# of displacements & dpa/photon \\
\hline${ }^{1} \mathrm{H}$ & 0.166 & $9.87 \times 10^{-24}$ \\
\hline${ }^{2} \mathrm{H}$ & 0.018 & $1.09 \times 10^{-24}$ \\
\hline${ }^{3} \mathrm{H}$ & 0.006 & $3.79 \times 10^{-25}$ \\
\hline${ }^{3} \mathrm{He}$ & 0.003 & $1.81 \times 10^{-25}$ \\
\hline${ }^{4} \mathrm{He}$ & 0.998 & $5.93 \times 10^{-23}$ \\
\hline Recoiling nuclei & 0.353 & $2.09 \times 10^{-23}$ \\
\hline TOTAL & $\mathbf{1 . 5 4 4}$ & $\mathbf{9 . 1 8 \times 1 0 ^ { - 2 3 }}$ \\
\hline
\end{tabular}

\section{$\underline{3.2}$ BLIP irradiations}

Table 2 presents the calculated displacement damage resulting from energetic ions for the Ti-6Al-4V specimens irradiated by $\sim 190 \mathrm{MeV}$ protons in the BLIP irradiation. The majority of the ion-induced displacement damage is produced by the recoiling nuclei from proton-nuclear reactions (including spallation), followed by the alpha particles and protons. For $3.7 \times 10^{20}$ total 
UCB-NE-5015

Page 9 of 13

incident protons on the specimens, the displacement damage due to the energetic ions is 0.043 dpa.

A spectral averaged dpa cross section, $\sigma_{\mathrm{dpa}}$, of 852 barns was obtained from the SPECTER calculation for the proton-induced incident neutron energy flux spectrum. This value equates to $4.45 \times 10^{-23} \mathrm{dpa} /$ incident proton - or a displacement damage due to proton-nuclear reaction produced neutrons of $0.016 \mathrm{dpa}$. Notably, the dpa cross-section is about $60 \%$ higher for the proton irradiation experiment than for the photon-beam NLC positron target. This is due to a much larger neutron spectrum within the high-energy tail of the distribution, and is also apparent in the much larger cross sections for $\mathrm{He}$ and $\mathrm{H}$ gas production (3363 barns for producing an atomic part per million, appm, of He and 8444 barns for an appm $\mathrm{H}$ in the BLIP irradiations vs 128 barns for appm He and 358 barns for appm $\mathrm{H}$ in the proposed photon beam NLC target).

Thus the total displacement damage in the Ti-6Al-4V specimens in the BLIP proton irradiation experiment is approximately $0.06 \mathrm{dpa}$. Again, the damage is calculated to be predominantly produced by energetic ions, although the fraction of neutron damage is slightly larger at $27.5 \%$ compared to the photon-beam target.

Table 2. Calculated radiation damage for energetic ions as the number of displacements and dpa/incident photon.

\begin{tabular}{|c|c|c|}
\hline Ion & Weighted \# of displacements & dpa/photon \\
\hline${ }^{1} \mathrm{H}$ & 0.023 & $2.81 \times 10^{-25}$ \\
\hline${ }^{2} \mathrm{H}$ & 0.0097 & $1.20 \times 10^{-26}$ \\
\hline${ }^{3} \mathrm{H}$ & 0.0004 & $4.59 \times 10^{-27}$ \\
\hline${ }^{3} \mathrm{He}$ & 0.0004 & $4.23 \times 10^{-27}$ \\
\hline${ }^{4} \mathrm{He}$ & 0.028 & $3.46 \times 10^{-25}$ \\
\hline Recoiling nuclei & 9.422 & $1.17 \times 10^{-22}$ \\
\hline TOTAL & $\mathbf{9 . 4 7 5}$ & $\mathbf{1 . 1 7 \times 1 0 ^ { - 2 2 }}$ \\
\hline
\end{tabular}

\section{Irradiation effects in Ti-6Al-4V}

Ti-6Al-4V alloys have a duplex microstructure consisting of alpha (hexagonal close packed, hcp) and beta (body centered cubic, bcc) phases. Typical beta phase volume fractions range from about $10-20 \%$, and the beta phase typically forms as intergranular bands $[10,11]$. 
UCB-NE-5015

Page 10 of 13

Radiation effects studies in titanium alloys have shown substantial increases in the yield and ultimate strength of up to $500 \mathrm{MPa}$ and a corresponding decrease in uniform ductility for neutron and high energy proton irradiation at temperatures between 40 and $300^{\circ} \mathrm{C}[11,12]$. Although the data is limited, there is an indication that the strength increases will saturate by doses on the order of a few dpa. Microstructural investigations indicate that the dominant features responsible for the strength increases were dense precipitation of a $\beta$ (body-centered cubic) phase precipitate along with a high number density of dislocation loops $[11,12]$.

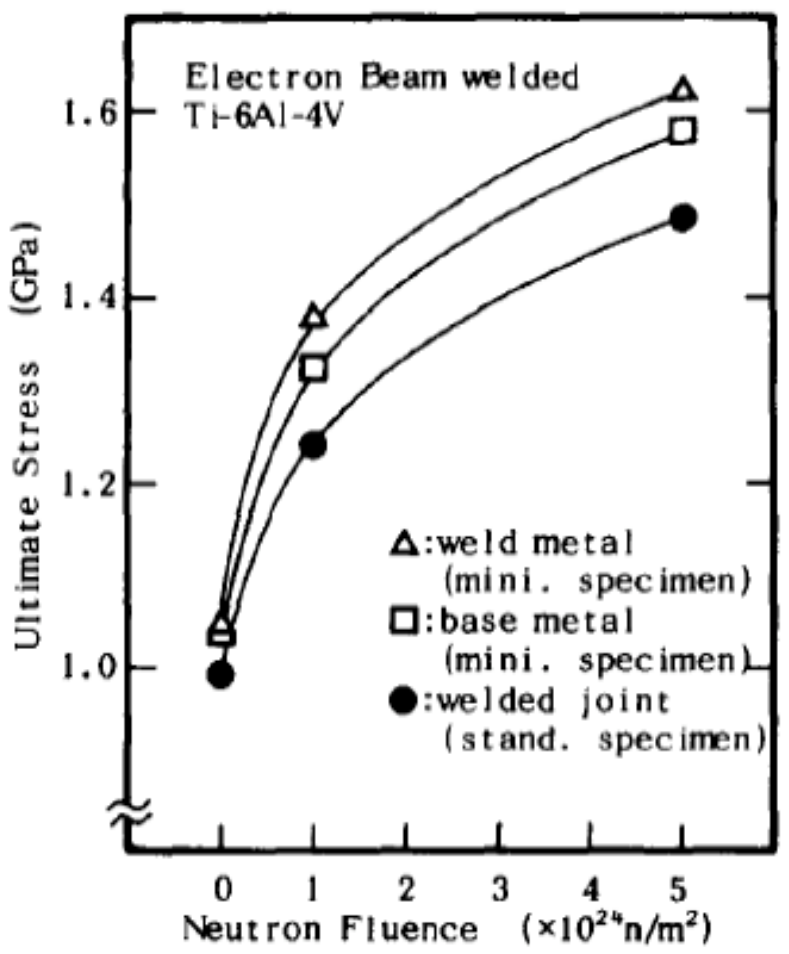

Figure 3. The effect of neutron irradiation on the ultimate tensile stress of Ti-6Al-4V alloy specimens in the as-received (base metal) and electron-beam welded conditions. The neutron fluence of $1 \times 10^{24} \mathrm{n} / \mathrm{m}^{2}$ corresponds to a dose of $0.05 \mathrm{dpa}$ and was performed at $150^{\circ} \mathrm{C}$, while the neutron fluence of $5 \times 10^{24} \mathrm{n} / \mathrm{m}^{2}$ corresponds to $0.25 \mathrm{dpa}$ and was performed at $270^{\circ} \mathrm{C}$ [12].

Kohyama and co-workers measured the increase of the ultimate tensile strength of Ti6Al-4V specimens as base metal and electron-beam welded specimens and joints following neutron irradiation to dose levels of 0.05 and $0.25 \mathrm{dpa}$ at temperatures of 150 (0.05 dpa) and $270^{\circ} \mathrm{C}(0.25 \mathrm{dpa})$ [12]. The data are shown in Figure 3. For the base metal, the ultimate tensile stress increases by more than $500 \mathrm{MPa}$ at a dose of $0.25 \mathrm{dpa}$. The curves in Figure 3 have been 
UCB-NE-5015

Page 11 of 13

drawn consistent with a saturating value of the ultimate tensile stress at higher dose, although it is important to note that the tendency towards saturation is difficult to judge due to the different irradiation temperatures.

Marmy and Leguey irradiated Ti-6Al-4V with a $590 \mathrm{MeV}$ proton beam at a dose rate of $\sim 3 \times 10-6 \mathrm{dpa} / \mathrm{sec}$ and irradiation temperatures of 40 to $350^{\circ} \mathrm{C}$ to doses of $0.01,0.1,0.2$ and 0.3 dpa [11]. Figure 4 shows the Marmy and Leguey yield and ultimate stress (Fig. 4a) and uniform and total ductility (Fig. 4b) as a function of irradiation temperature for Ti-6Al-4V irradiated to $0.3 \mathrm{dpa}$. The data indicates yield stress increases of about $400 \mathrm{MPa}$ at all irradiation temperatures, although the absolute stress values decrease with increasing test temperature. The uniform ductility decreases to between 2 and 3\% following irradiation, as compared to $16-20 \%$ in the unirradiated specimens. Although the Marmy and Leguey paper discusses irradiations at doses below $0.3 \mathrm{dpa}$, it does not discuss the dose dependence (e.g., saturation).
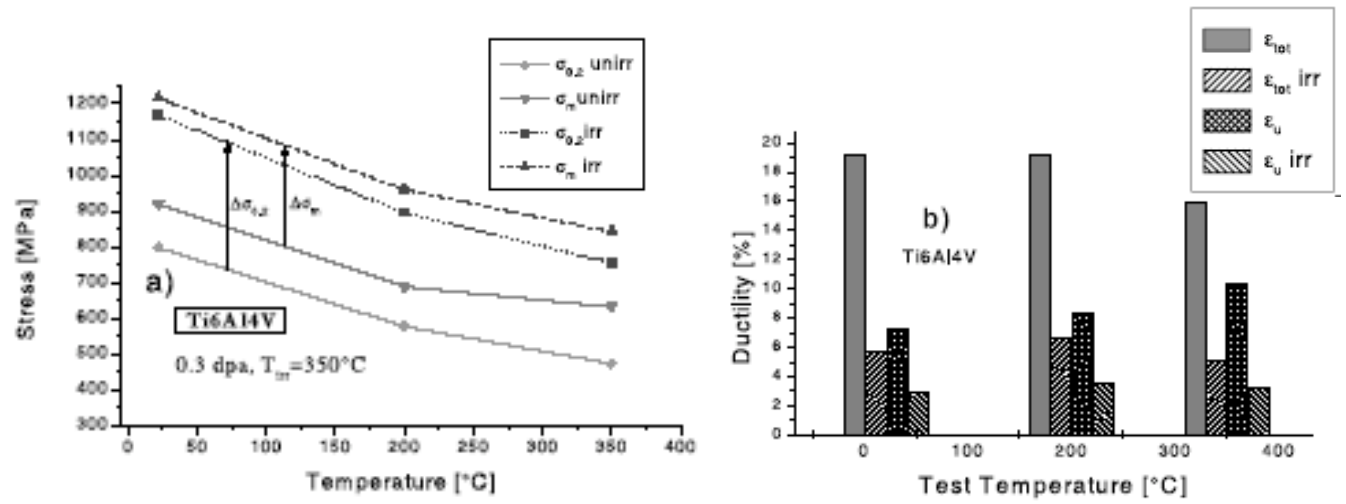

Figure 4. a) Yield and ultimate tensile stress of Ti-6Al-4V as a function of irradiation and test temperature. The irradiated specimens were proton irradiated to a dose of $0.3 \mathrm{dpa}$. b) Uniform and total ductility as a function of temperature for unirradiated and 0.3 dpa proton irradiated specimens. From reference [11].

Further irradiation effects studies are recommended in the dose range from 0.1 to $10 \mathrm{dpa}$ at irradiation temperatures from 30 to $300^{\circ} \mathrm{C}$ to provide additional data for model development and assessment of the property changes anticipated for the photon-beam NLC target. 
UCB-NE-5015

Page 12 of 13

\section{Summary and Recommendations}

Radiation damage produced by photon-nuclear and proton-nuclear interactions has been calculated for Ti-6Al-4V, which is being considered as a positron producing target for the next generation linear collider. The calculations involved combining FLUKA simulations of the highenergy particle interactions with SPECTER calculations of the neutron induced displacement cross sections, plus theoretical calculations based on the Lindhard model to determine the displacements produced by energetic ions. Radiation damage in the Ti-6Al-4V alloys was calculated for the positron target geometry associated with irradiation by 5 to $11 \mathrm{MeV}$ photons, in addition to the BLIP experiment, in which Ti-6Al-4V tensile specimens were irradiated with $\sim 190 \mathrm{MeV}$ protons. The calculation results indicate a damage rate of $\sim 0.8 \mathrm{dpa} / \mathrm{year}$ for the positron target (photon irradiated) and a damage level of 0.06 dpa in the BLIP irradiation experiment. Further, the calculations reveal that approximately $75 \%$ of the displacement damage results from the energetic ions, rather than the neutrons.

Irradiation effects studies in titanium alloys have shown substantial strengthening and decreases in ductility for irradiation at temperatures between 30 and $300^{\circ} \mathrm{C}$. Increases in the yield strength of about $500 \mathrm{MPa}$ and decreases in uniform ductility to about 2-3\% are observed for irradiation doses of $0.3 \mathrm{dpa}$. Further study is needed to determine whether the radiation strengthening and ductility loss will saturate with increasing dose.

Further radiation damage calculations, in particular a direct comparison of previous versus current calculations are recommended to determine the different relative damage production of ions versus neutrons in this as compared to previous studies. An experimental test matrix should focus on obtaining radiation strength and ductility changes over a range of doses from 0.1 to $10 \mathrm{dpa}$ to develop models of mechanical performance of the positron targets. This information, coupled with detailed modeling of the thermal-mechanical loading of the target will enable lifetime predictions.

\section{References}

[1] Zeroth-Order Design Report for the Next Linear Collider, LLNL internal report, UCRLID-124161 
UCB-NE-5015

Page 13 of 13

[2] Bharadwaj, V. K. et al., "Analysis of Beam-Induced Damage to the SLC Positron

Production Target”, Proc. PAC 2001, Chicago, IL, June 2001. (WPAH019).

[3] Caturla, M.J. et al., "Radiation damage induced by GeV electrons in W-Re targets for next generation linear colliders", UCRL-JC-148049.

[4] Caturla, M.J. et al., "Report on radiation damage effects in a titanium target under photon irradiation", UCRL-JC-149951.

[5] A.Fasso', A.Ferrari, P.R.Sala, "Electron-photon transport in FLUKA: status", Proceedings of the MonteCarlo 2000 Conference, Lisbon, October 23-26 2000, A.Kling, F.Barao, M.Nakagawa, L.Tavora, P.Vaz - eds., Springer-Verlag Berlin, p.159-164 (2001).

[6] A.Fasso', A.Ferrari, J.Ranft, P.R.Sala, "FLUKA: Status and Prospective for Hadronic Applications", Proceedings of the MonteCarlo 2000 Conference, Lisbon, October 23-26 2000, A.Kling, F.Barao, M.Nakagawa, L.Tavora, P.Vaz - eds. , Springer-Verlag Berlin, p.955-960 (2001).

[7] L. R. Greenwood, R. K. Smither, "SPECTER: Neutron Damage Calculationsfor materials Irradiations", ANL/FPP/TM-197, Argonne, IL, January 1985.

[8] Olander, D.R., 1976, Fundamental Aspects of Nuclear Reactor Fuel Elements, TID26711-P1, National Technical Information Services.

[9] Robinson, M.T., 1994, J. Nucl. Mater. 216, 1.

[10] ASM Handbooks, Volume 2 - Titanium Alloys, ASM International.

[11] Marmy, P. and Leguey, T., 2001, J. Nucl. Mater. 296, 155.

[12] Kohyama, A. et al., 1986, J. Nucl. Mater. 141-143, 987. 